\title{
Determinants of High Fertility among Ever Married Women in Enderta District, Tigray Region, Northern Ethiopia
}

Gezae Atsbaha ${ }^{1}$, Desta Hailu²,3*, Hailemariam Berhe ${ }^{2}$, Azeb G Slassie $^{2}$, Dejen Yemane ${ }^{2}$ and Wondwossen Terefe ${ }^{2}$

${ }^{1}$ Regional Health Bureau, Tigray Regional State, Ethiopia

${ }^{2}$ College of Health Sciences, Mekelle University, Ethiopia

${ }^{3}$ College of Medicine and Health Sciences, Arba Minch University, Ethiopia

\begin{abstract}
Background: Fertility is one of the major components of population dynamics, which determine the size and structure of a population. According to Ethiopian Demographic and Health Survey 2011 report, the total fertility rate is decreasing from 5.5 children in 2000 to 4.8 in 2011 . However, the rate of decline has been very slow as compared to the developed world. Thus, the objective of this study was to determine the magnitude and factors associated with high fertility among ever married women aged 25-49 years in Northern Ethiopia.

Methods: A community based cross-sectional study was conducted on randomly selected 531 subjects in Enderta district using an interviewer administered questionnaire. A multistage sampling technique was used to draw the study participants. Data were collected using a pretested and structured questionnaire from March 10-19/2013. The study participants' fertility was categorized as high and low. The collected data were coded, entered, and cleaned. Bivariate and multivariable logistic regression was used to analyze the variables at $p$-value $<0.05$.

Results: This study showed that $51 \%$ of the respondents had high fertility. Women who got married at the age of less than 18 years were 2.63 times $(\mathrm{AOR}=2.63,95 \% \mathrm{Cl}$ : $([1.526,4.528])$ more likely to have higher fertility as compared to those who got married at 18 years or more. Similarly, women with history of under five child mortality were 3.57 times $(A O R=3.57,95 \% \mathrm{Cl}:[1.884,6.779])$ more likely to have higher fertility when compared to those who had no history of under-five child mortality.

Conclusion: About half of the respondents had high fertility. Age at first marriage, under five child mortality, educational status of the women, current age of the women and age at first birth were found to be statistically significant. Thus, information, education and communication (IEC) should be strengthened to create awareness mainly among women and their husbands about the negative consequence of early marriage, early child birth and high fertility rate.
\end{abstract}

Keywords: Total fertility rate; Associated factors; Cross sectional study

\section{Background}

Fertility is one of the major components of population dynamics, which determine the size and structure of a population [1]. In the pretransition period it was left to biological conditions like age, intrauterine mortality, and postpartum amenorrhea while now days it is under complete control of couples and individuals [2].

Globally, total fertility decreased from an average of 4.7 children per woman in 1970-1975 to 2.6 children per woman in 2005-2010. This change was driven mostly by developing countries, whose fertility dropped by around half (from 5.6-2.5 children per woman). The decline was less marked among the least developed countries where fertility remains high. In those countries, fertility declined from 6.3 children per woman in 1970-1975 to 4.4 in 2005-2010 [3].

In sub-Saharan Africa, twenty nine countries including Ethiopia are characterized by high fertility $[4,5]$. Most of the sharp rise in population comes from sub-Saharan Africa and in parts of Asia (Pakistan and northern India) where the number of births will continue to grow well into the 2020's, even if fertility continues to drop. These are areas where the protection of adolescents and young women against early or unwanted pregnancy is most inadequate, mortality from unsafe abortion most pronounced, giving birth most hazardous and childhood most difficult to survive [6]. The Ethiopian population has increased fourfold between 1900 and 1988. This was different from the $2.9 \%$ annual growth rate suggested by the 1984 census. The total population in 1900 was estimated at 11.8 million. It took 60 years for this to double to 23.6 million in 1960 . Whereas, it took only 28 years for the population in 1960 to double to 47.3 million in 1988 in which higher population increase was seen [7].

According to Ethiopian population and housing census 2007 report, the population of Ethiopia had increased at a rate of $2.6 \%$ from 1994-2007. The population of the country has increased from $39,868,572$ in 1984 to $53,477,265$ in 1994 , and finally to $73,918,505$ in 2007. The total fertility rate has decreased from 5.5 children in 2000 to 5.4 children in 2005 and finally decreased to 4.8 in 2011 per woman. Despite slight decrement, still a single woman is having more than 4 children throughout her life. The total fertility rate in Tigray region was 4.6 children per woman [1]. Among the women in the age group of 1549 years, $40 \%$ have 6 and above living children. From women with 4 and above living children, $58 \%$ were still in desire to have more children $[1,8]$.

High fertility hinders achieving national goals such as food sufficiency, universal primary education, improving the accessibility of health care services to the largest possible number in the shortest

*Corresponding author: Desta Hailu, College of Health Sciences, Mekelle University, Ethiopia, Tel: +251-46881-4986; E-mail: destahailu30@yahoo.com

Received July 22, 2016; Accepted September 13, 2016; Published September 20, 2016

Citation: Atsbaha G, Hailu D, Berhe H, Slassie AG, Yemane D, et al. (2016) Determinants of High Fertility among Ever Married Women in Enderta District, Tigray Region, Northern Ethiopia. J Health Med Informat 7: 243. doi: 10.4172/21577420.1000243

Copyright: () 2016 Atsbaha G, et al. This is an open-access article distributed under the terms of the Creative Commons Attribution License, which permits unrestricted use, distribution, and reproduction in any medium, provided the original author and source are credited. 
possible time. Improving employment and housing conditions are remarkably difficult under high fertility conditions [3]. Mothers with higher parities have greater risk of death related to pregnancy and child birth and children from large family size have high risk of mortality and less chance of getting school $[4,5]$.

Some studies conducted in Gondar and Hawassa town shown that under five child mortality, age at first marriage, current marital status, income, decision making on contraceptive use were found to be significantly associated with fertility status [9-11]. However, studies addressing fertility status are scarce in the study area (Tigray region). Therefore, this study is intended to identify the factors associated with fertility status in Tigray region Enderta District, Ethiopia.

\section{Methods and Materials}

\section{Study setting and period}

This study was conducted in Enderta District from March 10-19, 2013. Enderta is one of the rural Districts in Tigray regional state. It is located $10.5 \mathrm{~km}$ east of Mekelle (the main city of Tigray) and 776.5 $\mathrm{km}$ north of Addis Ababa, the capital city of Ethiopia. The District is bordered from east, north, south, and west by Afar region, KilleteAwulaelo Woreda, Hintalo-wajirat, Saharti-Samire Woreda and Degua-Temben Woreda respectively. The number of women aged 1549 years was $23.5 \%(25,086)$ of the total population [12]. Regarding the health care service, it had six health centers and thirteen health posts both providing maternal and child health care service. Women and men literacy level was reported to be $13.64 \%$ and $16.07 \%$ respectively [13].

\section{Study design and populations}

A community based cross-sectional study design was conducted among randomly selected married women aged 25-49 years old in Enderta district. This group of women would be taken for this particular study given that women in Ethiopia are married at an early age and could have more than four children before they celebrate their twentyfifth birth day. The minimum age was therefore, set at 25 to give equal chance for the high and low fertile groups. Ever married women aged 25-49 years who were mentally and/or physically incapable and lived in Enderta district for less than six years were excluded from the study.

\section{Sample size determination and sampling procedure}

Single population proportion formula was used to determine the sample size as follows:

$$
\mathrm{n}=\frac{(\mathrm{Z} / 2) 2 \mathrm{p}(1-\mathrm{p})}{\mathrm{d} 2} \times \mathrm{D}
$$

Where n: Sample size needed, Za/2: Critical value at $95 \%$ confidence interval, P: Proportion of high fertility of from study conducted in Oromia region $=0.2[14]$.

$\mathrm{d}$ : margin of error $=0.05, \mathrm{D}$ : design effect which was determined to be 2 .

$$
\mathrm{n}=\frac{(1.96)(1.96)(0.2)(0.8)}{(0.05) 2} \times 2=492
$$

Moreover, $10 \%$ of the sample size was considered as non response rate to fill the gap from none respondents. Finally, the total sample size was calculated to be 541 .

Multistage sampling technique was used to select the study subjects. The District had a total of 17 kebeles/ smallest administrative unit in Ethiopia. Five kebeles were in the semi urban and 12 kebeles in the rural setting. The district was first stratified by residence in to semi urban and rural kebeles. Then, two Kebeles from semi urban and four kebeles from the rural setting were randomly selected using a lottery method. A total of six kebeles were selected from the district and the primary sampling units in this case were Kebels. From the six kebeles, six respective sub-kebeles were selected randomly using a lottery method which was taken as secondary sampling units. Women aged 25-49 years were identified and population frame was developed for each kebele from the log book of health extension workers/community based primary health care providers in Ethiopia. Then, sample size was proportionally allocated to each sub-kebeles. Households were selected by systematic random sampling. Every second house hold was selected from the sampling frame of each sub-kebele. If two women were in one household, only one respondent was considered using lottery method. From the four rural sub-kebeles, 346 ever married women with the age range of 25-49 were considered and from the two semi-urban sub-kebeles, 195 ever married women within the age group of 25-49 were taken. Among the respondents, six women were not voluntary to join the study because of being busy and they were considered as non-respondent. Moreover, four questionnaires were not properly filled and were discarded. Thus, a total of 10 questionnaires were excluded from the analysis and the sample size was reduced to 531 .

\section{Data collection methods}

A primary data was collected using an interviewer administered questionnaire developed by considering variables which were relevant to the study. Five health extension workers collected the data from March 10-19/2013 through home to home visit. One BSC nurse supervised the data collection process. The questionnaire was adopted from similar literatures and adapted to the local study context. The questionnaire was initially developed in English and then translated to the local language (Tigrigna). To check its consistency; it was translated back to English by an expert of both English and Tigrigna languages. Data collectors were trained for one day by the principal investigator to have a general over view of the study and methods of data collection procedures. Twenty eight (5\%) of the questionnaires were tested one week prior to the actual data collection at the nearby district (kiliteawlaelo). Based on the pretest findings, skip pattern of the questionnaire was improved and some ambiguous questions were modified. The pretest questionnaire was filled by health extension workers. The pretest data were not included in the analysis. During data collection there was a close supervision by the principal investigator and a supervisor. On a daily basis, $5 \%$ of the collected questionnaires were randomly selected and cross checked. Corrections were made on improperly filled questionnaires and the data collectors were informed about the mistakes and the way how they could make corrections.

\section{Data processing and analysis}

The collected data were coded and entered to SPSS version 20. Then, the data were cleaned and the variables were coded and categorized. Univariate analysis was made for each variable by describing frequencies and percentages. Logistic regression, both bivariate and multivariable analysis was carried out to test for the direction and magnitude of association between dependent and independent variables. The regression model was developed using a step wise regression technique. Confounders were tested at a cutoff point $15 \%$ change of coefficient. The final model was checked for interaction. Multicollinearity was checked at cut off point VIF $>10$ 
to test if the independent variables were related. The final model goodness of fit was checked by Hosmer-lemeshow test.

\section{Measurement}

The total fertility rate (TFR), sometimes also called the fertility rate of a population is the average number of children that would be born to a woman over her lifetime if she were to experience the exact current age-specific fertility rates (ASFRs) through her lifetime, and she were to survive from birth through the end of her reproductive life. Fertility status was measured by the number of children ever born alive to a woman: It is categorized as low fertility when children ever born alive were $<5$ and high fertility when children ever born alive were $\geq 5$. The cutoff point of 5 is taken because the medical and obstetric risks for mothers with a number of children ever born alive greater or equal to 5 are significantly higher compared with those with less than 5 . It is also based on the classification of the population policy of Ethiopia.

\section{Outcome and exposure measures}

The outcome variable was fertility status measured by the number of children ever born alive to a woman. Dummy variables were created as: Women having less than five children (Low Fertility) and five and above children (High Fertility). High Fertility was coded as "1" and Low Fertility was coded as "0". Potential predictors such as marital status of the mother, educational status of the mother, religion of the mother, house hold monthly income, husband's educational status, age at first marriage, age at first child birth, age of the mother at interview, duration of breast feeding, history of under-five child mortality, Ever contraceptive use, exposure to media, history of abortion and still birth were included in the analysis.

\section{Ethical Consideration}

The study was conducted after institutional review board of Mekelle University, College of Health sciences approved that it would not harm participants and provided approval letter. A letter of cooperation was also provided from Tigray Regional Health Bureau to Enderta District Health Office. At the beginning of the data collection, informed consent was obtained from each respondent after through explanation of the purpose and the procedures of the study. Detailed personal information like name of the participant was not recorded to ensure that confidentiality was kept.

\section{Result}

A total of 531 ever married women aged 25-49 years old were included in this study. The response rate was $99 \%$ that is from 541 questionnaires 531 were included in the analysis. Religion and mother's occupation variables were excluded from the analysis because all of the interviewed women's religion was orthodox and their occupation was house wives. From the respondents, 270 (51\%) had high fertility.

\section{Socio-demographic characteristics of participants}

Among the respondents, 263 (50\%) were within the age range of 25-34 years, and 193 (36\%) were within the age of group 35-44 years. Three hundred ninety four $(74 \%)$ got married for the first time. Age at first birth was less than 18 years for 223 (42\%) of the mothers. Three hundred eighty six (73\%) were illiterate, and $87(16 \%)$ were able to read and write. When asked about the educational status of their husbands, they reported that 266 (56\%) were illiterate, and 149 (32\%) were with the ability to read and write. Monthly income of 413 (78\%) of the respondents was below 684 birr and $82(15 \%)$ of the respondents were with history of under-five child mortality (Table 1).

\begin{tabular}{|c|c|c|c|}
\hline & Variables & Frequency & $\%$ \\
\hline \multirow{2}{*}{ Fertility status } & High fertility & 270 & 50.85 \\
\hline & Low fertility & 261 & 49.15 \\
\hline \multirow{3}{*}{ Age at interview } & $25-34$ & 263 & 49.53 \\
\hline & $35-44$ & 193 & 36.35 \\
\hline & $\geq 45$ & 75 & 14.12 \\
\hline \multirow{2}{*}{ Age at first marriage } & $<18$ years & 394 & 74.20 \\
\hline & $\geq 18$ years & 137 & 25.80 \\
\hline \multirow{2}{*}{ Age at first child birth } & $<18$ years & 223 & 42.00 \\
\hline & $\geq 18$ years & 308 & 58.00 \\
\hline \multirow{3}{*}{ Educational status of women } & Illiterate & 386 & 72.69 \\
\hline & Read and write & 87 & 16.38 \\
\hline & Primary and above & 58 & 10.92 \\
\hline \multirow{3}{*}{$\begin{array}{l}\text { Husband's educational status } \\
\qquad(\mathrm{n}=471)\end{array}$} & Illiterate & 266 & 56.48 \\
\hline & Read and write & 149 & 31.63 \\
\hline & Primary and above & 56 & 11.89 \\
\hline \multirow{2}{*}{ Monthly income } & $<684$ ETB & 413 & 77.78 \\
\hline & $\geq 684$ ETB & 118 & 22.22 \\
\hline \multirow{2}{*}{ Marital status } & Married & 471 & 88.70 \\
\hline & Divorced/widowed & 60 & 11.30 \\
\hline \multirow{2}{*}{ History of under-five child mortality } & Yes & 82 & 15.44 \\
\hline & No & 449 & 84.56 \\
\hline \multirow{2}{*}{ Still birth } & Yes & 47 & 8.85 \\
\hline & No & 484 & 91.15 \\
\hline \multirow{2}{*}{ Spontaneous abortion } & Yes & 24 & 4.52 \\
\hline & No & 507 & 95.48 \\
\hline \multirow{2}{*}{ Induced abortion } & Yes & 11 & 2.07 \\
\hline & No & 520 & 97.93 \\
\hline \multirow{2}{*}{ Listens to radio/television } & Yes & 390 & 73.45 \\
\hline & No & 141 & 26.55 \\
\hline \multirow{2}{*}{ Ever contraceptive use } & Yes & 452 & 85.12 \\
\hline & No & 79 & 14.88 \\
\hline Duration of breast feeding & $\begin{array}{l}<17 \text { months } \\
18-24 \text { months } \\
>24 \text { months }\end{array}$ & $\begin{array}{c}39 \\
290 \\
202\end{array}$ & $\begin{array}{l}7.34 \\
54.61 \\
38.04\end{array}$ \\
\hline
\end{tabular}

Table 1: Background characteristics of respondents in Enderta district, Northern Ethiopia, 2013.

\section{Factors affecting fertility rate of participants}

In bivariate analysis, current age of women, educational level of women, age at first marriage, want to have more children, history of under-five child mortality and age at first birth were statistically significant. Women with in the age range of 35-44 years were about 6 times (COR=6.17, 95\% CI: 4.097, 9.305) more likely to have high fertility than women with the age group of 25-34 years and women with the age of 45 years and above were 13.93 times (COR=13.93, 95\% CI: $7.097,27.332$ ) more likely to have high fertility than women with the age group of 25-34 years. The odds of having high fertility rate was 5.19 times $(\mathrm{COR}=5.19,95 \% \mathrm{CI}: 2.664,10.106)$ higher for illiterate women than women with educational level of primary and above where as women who can read and write were 2.71 times $(\mathrm{COR}=2.71,95 \%$ CI: $1.259,5.817)$ more likely to have high fertility than women with educational level of primary and above.

Women who got married at the age below 18 years were about 4 times (COR=3.56, 95\% CI: 2.336, 5.430) more likely to have high fertility rate than women who got married at the age 18 years and above. Women who have given their first birth at the age below 18 years were 2.31 times $(\mathrm{COR}=2.31,95 \% \mathrm{CI}: 1.622,3.288)$ more likely to be with higher fertility than women who have given their first birth at the age 18 years and above. Women who did not want to have more children 
were 2.28 times $(\mathrm{COR}=2.28,95 \% \mathrm{CI}: 1.609,3.228)$ more likely to have higher fertility than women who want to have more children. Women with history of under five child mortality were 3.34 times $(\mathrm{COR}=3.34$, 95\% CI: 1.964, 5.664) more likely to have higher fertility than women who did not have history of under five child mortality.

In multivariable analysis age at interview, women educational status, age at first marriage and history of under-five child mortality were found to be independent predictors of the outcome variable (Table 2). Women with the age group of 35-44 years were 5.67 times $(\mathrm{AOR}=5.67,95 \% \mathrm{CI}: 3.629,8.853)$ more likely to have high fertility than women with the age group 25-34 years and women with the age 45 years and above were 10.16 times $(\mathrm{AOR}=10.16,95 \% \mathrm{CI}: 4.987$, 20.694) more likely to have higher fertility than women with the age group 25-34 years. Illiterate women were 3.02 times $(\mathrm{AOR}=3.02,95 \%$ CI: $1.423,6.390)$ more likely to have higher fertility than women with primary and above education. Women who were married at age below 18 years were 2.63 times $(\mathrm{AOR}=2.6395 \% \mathrm{CI}: 1.526,4.528)$ more likely to have higher fertility than women who were married at age 18 years and above. Women with history of under five child mortality were 3.57 times (AOR=3.57, 95\% CI: $1.884,6.779$ ) more likely to have higher fertility than women who have no history of under-five child mortality. Women who have given their first birth below 18 years were $1.62(\mathrm{AOR}=1.62,95 \% \mathrm{CI}: 1.011-2.592)$ times more likely to have higher fertility than women who have given their first birth at 18 years and above, after adjusting for age of women, educational level of women, age at first marriage and history of under-five child mortality.

Model goodness of fit was tested by Hosmer-Lemeshow test which measures the correspondence between observed and expected values of the dependent variable. Better model fitness was indicated by smaller difference between the observed and expected values or larger p-value. The model in this study was found with a p-value of 0.6576 which indicated smaller difference between observed and expected difference. The model prediction power was checked by ROC curve and it was $82 \%$. This indicated that $82 \%$ of the model was described by the independent variables found in the final model. The final model was also checked for confounders at $15 \%$ change in coefficient when the suspected confounder is in and out of the model.

\section{Discussion}

Identifying factors related to high fertility is of paramount importance for successful implementations of population policies

\begin{tabular}{|c|c|c|c|c|c|}
\hline \multirow{2}{*}{\multicolumn{2}{|c|}{ Variables $(n=531)$}} & \multicolumn{2}{|c|}{$\begin{array}{c}\text { Fertility } \\
\text { Status }\end{array}$} & \multirow{3}{*}{\begin{tabular}{|c|}
$\begin{array}{c}\text { Crude OR } \\
\text { CI) }\end{array}$ \\
1
\end{tabular}} & \multirow{3}{*}{$\begin{array}{c}\begin{array}{c}\text { Adjusted OR } \\
(\mathbf{9 5 \%} \mathrm{Cl})\end{array} \\
1\end{array}$} \\
\hline & & High & Low & & \\
\hline \multirow{3}{*}{$\begin{array}{c}\text { Age at } \\
\text { interview }\end{array}$} & $25-34$ & 72 & 191 & & \\
\hline & $35-44$ & 135 & 58 & $6.17(4.10-9.31)$ & 5.67 (3.63-8.85) \\
\hline & $\geq 45$ & 63 & 12 & $13.93(7.10-27.33)$ & $10.16(4.99-20.69)$ \\
\hline \multirow{3}{*}{$\begin{array}{c}\text { Educational } \\
\text { status of } \\
\text { women }\end{array}$} & Illiterate & 222 & 164 & $5.19(2.66-10.11)$ & $3.02(1.42-6.39)$ \\
\hline & $\begin{array}{l}\text { Read and } \\
\text { write }\end{array}$ & 36 & 51 & $2.71(1.26-5.82)$ & $1.84(0.77-4.39)$ \\
\hline & $\begin{array}{l}\text { Primary\& } \\
\text { above }\end{array}$ & 12 & 46 & 1 & 1 \\
\hline \multirow{2}{*}{$\begin{array}{l}\text { Age at first } \\
\text { marriage }\end{array}$} & $<18$ years & 231 & 163 & $3.56(2.34-5.43)$ & $2.63(1.53-4.53)$ \\
\hline & $\geq 18$ years & 39 & 98 & 1 & 1 \\
\hline \multirow{2}{*}{$\begin{array}{c}\text { History of } \\
\text { under-five child } \\
\text { mortality }\end{array}$} & Yes & 61 & 21 & $3.34(1.96-5.66)$ & $3.57(1.88-6.78)$ \\
\hline & No & 209 & 240 & 1 & 1 \\
\hline \multirow{2}{*}{$\begin{array}{l}\text { Age at first } \\
\text { child birth }\end{array}$} & $<18$ years & 140 & 83 & $2.31(1.62-3.29)$ & 1.62 (1.01- 2.59) \\
\hline & $\geq 18$ years & 130 & 178 & 1 & 1 \\
\hline
\end{tabular}

Table 2: Multivariate logistic regression of fertility status against its predictors of among women in Enderta district, Northern Ethiopia, 2013. to reduce fertility rate. Therefore, this study intended to determine factors associated with high fertility among ever married women aged 25-49 years.

This study revealed that $51 \%$ of the respondents had high fertility and $49 \%$ were with low fertility. This finding is nearly in line with a study conducted in North and South Gondar zones, Amhara province [10]. However, it was higher than a study finding from Oromia region Kersa district [14]. This variation might be due to the fact that the median age for marriage in Tigray region is smaller than Oromia region.

Women within the age group 35-44 years and those aged 45 years and above had higher fertility than women aged 25-34 years. This finding was similar to a study conducted in Pakistan [15]. The significance of this variable might be attributed to women who are older were with high fertility due to the longer time they lived. They may have higher probability of having children.

Illiterate women were found to have higher fertility rate when compared with women who had primary and above educational level. This finding is in agreement with evidence from Hawassa, and Saudi Arabia $[10,16]$. The possible explanations might be educated women have better access to health service information, improved perceptions of the causes of disease and can utilize health information optimally. In addition, educated women have greater autonomy to make decisions to avoid early marriage and child birth. Moreover, educated women are more likely to spend many years in school and so they can increase their age when they get married and this could help in decreasing the number of children they can have. However, it contradicts with the study conducted in Butagira [17]. This variation might be due to the difference in time and design of the studies conducted.

Women who got married at the age of less than 18 years had higher fertility than those who got married at age 18 years or more. The reason behind can be because of the fact that women who got married at their early age have the probability of having many children since many years are remaining to reach their age of menopause (age menstrual cycle ends) from their age at marriage. In addition, women who got married at early age might be either leaving school or do not attend school which is indirectly related to education as discussed above. This finding was similar to studies conducted in Gondar zones, Pakistan, India and Sub-Saharan Africa $[10,15,18,19]$. However, this finding was different from study conducted in Oromia region Kersa district [14]. This variation might be due to the difference in selection of study subjects by age. The study participants in Kersa district were with the age group 20-49 years whereas; in this study they were in the age range of 25-49 years. According to Ethiopian demographic and health survey, the median age at first marriage is higher for women within the age group 20-49 years than women with the age group 25-49 years.

Women with history of under-five child mortality were with higher odds of fertility than women with no history of under-five child mortality. This can be partly explained by the fact that women who have history of under-five child mortality want to replace their child although they afraid that they would face the same problem. Previous studies reported similar evidence [10,14,20-22]. Women who have given their first birth below 18 years were with higher fertility rate than women who have given their first birth 18 years and above. This might be explained by the fact that women with early birth have many years remaining to stop child bearing or to reach the age when reproduction ends. This finding is similar with previous reports from Africa [14,23-27].

When interpreting the findings of this study some limitations should be considered. The cross sectional nature of the data made it impossible to establish causal relationships. Besides, the source of data 
Citation: Atsbaha G, Hailu D, Berhe H, Slassie AG, Yemane D, et al. (2016) Determinants of High Fertility among Ever Married Women in Enderta District, Tigray Region, Northern Ethiopia. J Health Med Informat 7: 243. doi: 10.4172/2157-7420.1000243

for this study was based on the self-report of respondents, and provided no validation of obtaining information with any objective source.

\section{Conclusion}

In this study, about half of the respondents had high fertility. Age at first marriage, age at first birth, educational status of women, age at interview and history of under-five child mortality were found to be independent predictors of high fertility rate. Age at first marriage and age at first birth were negatively associated with high fertility rate.

\section{Recommendation}

Thus, to optimize fertility status of women, the community in general and mothers in particular should be mobilized to create awareness on the negative consequence of early marriage and giving birth. Women should also be encouraged to pursue their education up to the higher level and the reason for their drop out from school should be identified. Moreover, health extension program should be strengthened to improve sanitation, nutritional status and vaccination of under-five children to bring child mortality down. Finally, further research should be conducted on fertility status using robust analytical study designs such as prospective cohort and case control.

\section{Author Contribution}

Atsbaha $\mathrm{G}$ designed the study, participated in the data collection, performed analysis and interpretation of data and drafted the paper and prepared all versions of the manuscript. Slassie AG, Yemane D, Terefe W, Hailu D, Berhe H assisted in the design, approved the proposal with some revisions, participated in data collection, analysis and revised subsequent drafts of the paper. All authors read and approved the final manuscript.

\section{Acknowledgements}

We are grateful to Mekelle University and Tigray regional Health bureau for their technical and financial support respectively. We would also like to extend our gratitude to all study participants for their cooperation and commitment in responding to our interviews and to our data collectors and supervisors for their extensive devotion at fieldwork.

\section{References}

1. Central Statistical Agency (2012) Ethiopia Demographic and Health Survey Fertility trends: Addis Ababa, Ethiopia and Calverton, Maryland.

2. Bart D (2006) Fertility Theories, Frame works, Models, Concepts: Netherlands interdisciplinary demographic institute. The Netherlands.

3. United Nations Department Economic and Social Affairs (UNDESA) (2009) World Fertility Patterns: New York.

4. World Economic Forum (2012) Global agenda council on population growth 2012-2014.

5. (2010) Determinants and Consequences of High Fertility Report: A Synopsis of the Evidence. Washington, D.C., USA.

6. World Health Organization (2005) Make every mother and child count Switzerland.
7. Office of the Prime Minister (1993) National population policy of Ethiopia: Addis Ababa.

8. Central Statistical Agency (2007) Population and Housing Census. Statistical Report: central statistical agency. Addis Ababa, Ethiopia.

9. WHO, UNICEF, UNFPA, World Bank Estimates (2012) Trends in maternal mortality 1990 to 2010: World Health Organization; Switzerland.

10. Gebremedhin S, Betre M (2009) Level and differentials of fertility in Awassa town, Southern Ethiopia. Afr J Reprod Health 13: 93-112.

11. Alene GD, Worku A (2008) Differentials of fertility in North and South Gondar zones, northwest Ethiopia: a comparative cross-sectional study. BMC Public Health 8: 397.

12. (2013) Finance, economic and health office joint annual report: Tigray region, Enderta district.

13. (2012) Statistical agency annual report. Tigray region, Enderta district.

14. Belayihun B (2011) Determinants of high fertility status among married women in Oromia region, Kersa district.

15. Kemal A, Khalid M (2011) Factors Affecting Family Size in Pakistan. J Statistics 18: 29-53.

16. Kharif R (2011) Fertility in Saudi Arabia. Levels and Determinants. King Saudi University: Saudi Arabia.

17. Mekonnen W, Worku A (2011) Determinants of fertility in rural Ethiopia: the case of Butajira Demographic Surveillance System (DSS). BMC Public Health 11: 782

18. Mishra Vinod K (2004) Moslems/Non-Muslims differentials in fertility and family planning in India. East-West working papers population \& health series No. 112

19. Bongaarts J, Casterline J (2013) Fertility Transition: Is sub-Saharan Africa Different? Popul Dev Rev 38: 153-168.

20. Hakim A (1999) Demographic, socio-economic and regional fertility differentials Pakistan. Pak Dev Rev 38: 643-660.

21. Al-Kandari YY (2007) Fertility and its relationship with sociocultural factors in Kuwaiti society. East Mediterr Health J 13: 1364-1371.

22. Adhikari R (2010) Demographic, socio-economic, and cultural factors affecting fertility differentials in Nepal. BMC Pregnancy Childbirth 10: 19.

23. Indongo N, Pazvakawambwa L (2012) Determinants of fertility in Namibia. Afr J Reprod Health 16: 50-57.

24. Fitaw Y, Berhane Y, Worku A (2004) Impact of child mortality and fertility preferences on fertility status in rural Ethiopia. East Afr Med J 81: 300-306.

25. Alemayo T, Haider J, Habte (2010) Determinants of adolescent fertility in Ethiopia using EDHS 2005 and 2010. Ethiop J Health Dev.

26. Mathew $\mathrm{O}$ (2012) Determinants of fertility among women of child bearing age in Nigeria. Afr J Reprod Health.

27. Bongarts J (2010) Poverty, Gender and Youth; The causes of educational differences in fertility in Sub-Saharan Africa: Population council, New York, USA. 